\title{
SCALE-UP OF THE NITRIDATION AND SINTERING OF SILICON PREFORMS USING MICROWAVE HEATING
}

\author{
J. O. Kiggans, Jr.*, T. N. Tiegs*, C. C. Davisson*, M. S. Morrow** and G. J. Garvey*** \\ *Oak Ridge National Laboratory, Oak Ridge, Tenn., 37831-6087 \\ **Y-12 Development Division, Oak Ridge, Tenn., 37831-8096 \\ ***Golden Technologies, Inc., Golden, Colo.; Presently, Ceradyne, Inc. Costa Mesa, CA.
}

\begin{abstract}
:
Scale-up studies were performed in which microwave heating was used to fabricate reactionbonded silicon nitride and sintered reaction-bonded silicon nitride (SRBSN). Tests were performed in both a $2.45 \mathrm{GHz}, 500$ liter and a $2.45 \mathrm{GHz}, 4000$ liter multimode cavities. A variety of sizes, shapes, and compositions of silicon preforms were processed in the studies, including bucket tappets and clevis pins for diesel engines. Up to 230 samples were processed in a single microwave furnace run. Data were collected which included weight gains for nitridation experiments, and final densities for nitridation and sintering experiments. For comparison, nitridation and sintering studies were performed using a conventional resistance-heated furnace.
\end{abstract}

\section{INTRODUCTION}

Silicon nitride materials represent a class of materials having a wide range of compositions where silicon nitride $\left(\mathrm{Si}_{3} \mathrm{~N}_{4}\right)$ is the major phase. These materials are of interest in numerous applications for such diverse items as cutting tools, rotors and stator vanes for advanced gas turbines, valves and cam roller followers for gasoline and diesel engines, and radomes on missiles. ${ }^{1}$ However, these materials tend to be very expensive and are not competitive on a cost basis with metal parts. ${ }^{2}$

SRBSN, made from silicon, has been identified as a cost-effective alternative to $\mathrm{Si}_{3} \mathrm{~N}_{4}$ made from high cost $\mathrm{Si}_{3} \mathrm{~N}_{4}$ powders. Silicon is economical compared to high purity $\mathrm{Si}_{3} \mathrm{~N}_{4}$ powders (approximately $1 / 4$ the cost). In addition, SRBSN materials are attractive in that they exhibit improved control over the dimensional tolerances due to less shrinkage during sintering. ${ }^{3,4}$

In the last few years, microwave heating has been investigated extensively for use in the thermal processing of ceramics. 5 .9 In addition, the microwave processing of $\mathrm{Si}_{3} \mathrm{~N}_{4}$ has been the focus of considerable research. ${ }^{.0-16}$

\section{EXPERIMENTAL PROCEDURES}

\section{Nitridation Scale-Up Study}

Silicon preforms of a clevis pin geometry were supplied by Golden Technologies, Inc., Golden, Co., as part of a Cooperative Research and Development Agreement (CRADA) sponsored by Department of Energy with the Oak Ridge National Laboratory. The composition of the clevis pins is proprietary information. The pins are a cylindrical shape, $3.84 \mathrm{~cm}$ long by $1.18 \mathrm{~cm}$ diameter, with a $0.24 \mathrm{~cm}$ diameter hole through center and parallel to the longitudinal axis.

Scale-up microwave nitridation processing of the preforms was conducted in an ORNL, 500 liter cylindrical multimode cavity, equipped with dual $6 \mathrm{~kW}, 2.45 \mathrm{GHz}$ power generators. The clevis pins were placed inside one of two rectangular-shaped sample crucibles having walls composed of 40,60 , or $80 \mathrm{wt} \% \mathrm{SiC}$ with a balance of $\mathrm{Si}_{3} \mathrm{~N}_{4}$ and $\mathrm{Y}_{2} \mathrm{O}_{3}$, and with the crucible top and bottom composed of hot-pressed boron nitride. One crucible measured $9.5 \mathrm{~cm}$ by $10.8 \mathrm{~cm}$ by $4.4 \mathrm{~cm}$, and the larger crucible measured $15 \mathrm{~cm}$ by $16.8 \mathrm{~cm}$ by $4.4 \mathrm{~cm}$. Each sample crucible was placed inside a $2.5 \mathrm{~cm}$ thick alumina fiberboard insulation casket inside the microwave furnace. The furnace was evacuated twice to 800 millitorr and backfilled with nitrogen, and then evacuated and backfilled with $\mathrm{N}_{2}-4 \mathrm{vol} \% \mathrm{H}_{2}$. Nitridation was performed at a final temperature of $1300^{\circ} \mathrm{C}$. Temperatures were measured continuously during processing using a molybdenum-sheathed type " $C$ " thermocouple. Complete details of experiments have been reported elsewhere. ${ }^{17}$

"The submitted manuscript has been authored by a contractor 
Clevis pins were weighed before and after experiments, and weight gain values calculated to determine the extent of nitridation.

\section{Nitridation and Sintering Scale-Up Study}

Three types of silicon preforms were used for the nitridation and sintering scale-up study: gelcastisopressed preforms fabricated by ORNL; die-pressed silicon preforms purchased from Coors Ceramics Co.; and injection-molded bucket tappet preforms purchased from the Cremer Forschungs Institut Gmbh and Co., Rödental Germany. Further details concerning preparation, sizes, and compositions of the various preforms have been reported. ${ }^{12-14}$

Scale-up microwave nitridation and sintering experiments were conducted in the ORNL, 500 liter cavity and in a 4000 liter multimode cavity, which is equipped with eight, $6 \mathrm{~kW}, 2.45 \mathrm{GHz}$ power generators. Eight to 230 samples, with masses ranging from 9 to $32 \mathrm{~g}$ each, were processed in each experiment. Microwave furnaces were evacuated and backfilled with $\mathrm{N}_{2}$ and then $\mathrm{N}_{2}-4$ vol $\% \mathrm{H}_{2}$ prior to start of the heating cycle. Each microwave experiment was conducted in a single heating cycle. Conventional nitridation and sintering experiments were conducted in a graphiteresistance heated furnace in two separate furnace runs using flowing $\mathrm{N}_{2}-4 \mathrm{vol} \mathrm{\%} \mathrm{H}_{2}$ (nitridation run) or $\mathrm{N}_{2}$ (sintering run). The final sintering temperature for the microwave and conventional experiments ranged from 1750 to $1800^{\circ} \mathrm{C}$. Samples were weighed before and after experiments, and the densities of sintered pieces were measured using the Archimedes method. Further details concerning experimental conditions for individual conventional and microwave heating experiments have been reported. ${ }^{13-15,18}$

\section{Results}

\section{Nitridation Scale-up Study}

This study was conducted in order to determine the proper crucible set-up for the scale-up of the microwave nitridation of silicon preforms. Table 1 summarizes the results obtained from a number of experiments. The first experiment involved the nitridation of 36 clevis pins, with $0.5 \mathrm{~cm}$ separating each pin, in the small $40 \mathrm{wt} \% \mathrm{SiC}$ crucible. SiC was included in this crucible as a surrogate material to absorb microwave energy and heat the crucible walls. The average nitridation weight gain was $43.5 \mathrm{wt} \%$, which is comparable to results obtained from a conventional nitridation. A closer look at data in experiment 1 indicates that the weight gain of samples along the inside edge of the crucible, "Edge CP," were comparable to the weight gain of samples completely surrounded by other samples, "Inside CP." However, some samples in the center of the crucible showed minor shrinkage due to sintering. To gain a further insight into the partial sintering of these samples, experiment 2 was performed. In this experiment, 60 clevis pins were in the same crucible with no separation between pins. Once again the weight gains were good, however the unwanted sintering of the center-most samples in the crucible increased. This result pointed out the need for more space between clevis pins to prevent spot sintering. In a larger scaleup experiment, experiment 3, eighty-one clevis pins were spaced at a greater distance, $0.65 \mathrm{~cm}$ from each other, in the large $40 \mathrm{wt} \% \mathrm{SiC}$ crucible. Table 1 shows that good nitridation was obtained with no shrinkage of "inside" samples, however, the statistical deviation of average weight gain rose slightly. Although the weight gain of the "Edge CP" samples appeared to be normal, a slight silicon color on the side of pins facing the crucible wall suggested that the temperature along the edge was lower than the center of the crucible.

Tests were conducted in crucibles of the same size as experiment 3 , but having walls made of 60 and $80 \mathrm{wt} \% \mathrm{SiC}$. The higher $\mathrm{SiC}$ additions to these crucibles were made to increase microwave heating of the crucibles. The results in Table 1 indicate that the standard deviation of the average densities improved by increasing the SiC content. Overall, the last three experiments showed that proper sample spacing eliminated undesirable localized sintering of samples, and that matching the absorption of microwaves by crucibles and samples resulted in a more uniform temperature distribution within the crucibles. Figure 1, visual evidence of the success of the microwave nitridation scale-up, shows the crucible arrangement of a microwave nitridation with 90 clevis pins using the 80 wt $\%$ SiC crucible set-up. 
Table 1. Summary of microwave nitridation scale-up experiments

$\begin{array}{ccccccc}\text { Exp\# } & \text { Sample \# } & \begin{array}{c}\text { Crucible } \\ \text { Type }\end{array} & \begin{array}{c}\text { Average } \\ \text { \%Wt Gain } \\ \text { "Total CP" }\end{array} & \begin{array}{c}\text { Average } \\ \text { \% Wt Gain } \\ \text { "Inside CP" }\end{array} & \begin{array}{c}\text { Average } \\ \% \text { Wt Gain } \\ \text { "Edge CP" }\end{array} & \begin{array}{c}\text { St. Dev. Average } \\ \% \text { Wt Gain } \\ \text { "Total CP" }\end{array} \\ 1 & 36 & 40 \mathrm{wt} \% \mathrm{SiC} & 43.49 & 43.49 & 43.50 & 0.14 \\ 2 & 60 & 40 \mathrm{wt} \% \mathrm{SiC} & 43.85 & 43.80 & 43.91 & 0.08 \\ 3 & 81 & 40 \mathrm{wt} \% \mathrm{SiC} & 43.83 & 43.73 & 43.98 & 0.16 \\ 4 & 81 & 60 \mathrm{wt} \% \mathrm{SiC} & 43.46 & 43.46 & 43.55 & 0.12 \\ 5 & 81 & \text { 80 wt \% SiC } & 43.82 & 43.78 & 43.88 & 0.09\end{array}$

${ }^{1} \mathrm{CP}=$ Clevis Pin

${ }^{2}$ Inside $\mathrm{CP}=$ clevis pins surrounded only by other samples

${ }^{3} \mathrm{Edge} \mathrm{CP}=$ clevis pins with the crucible wall on one side and samples on the opposite side

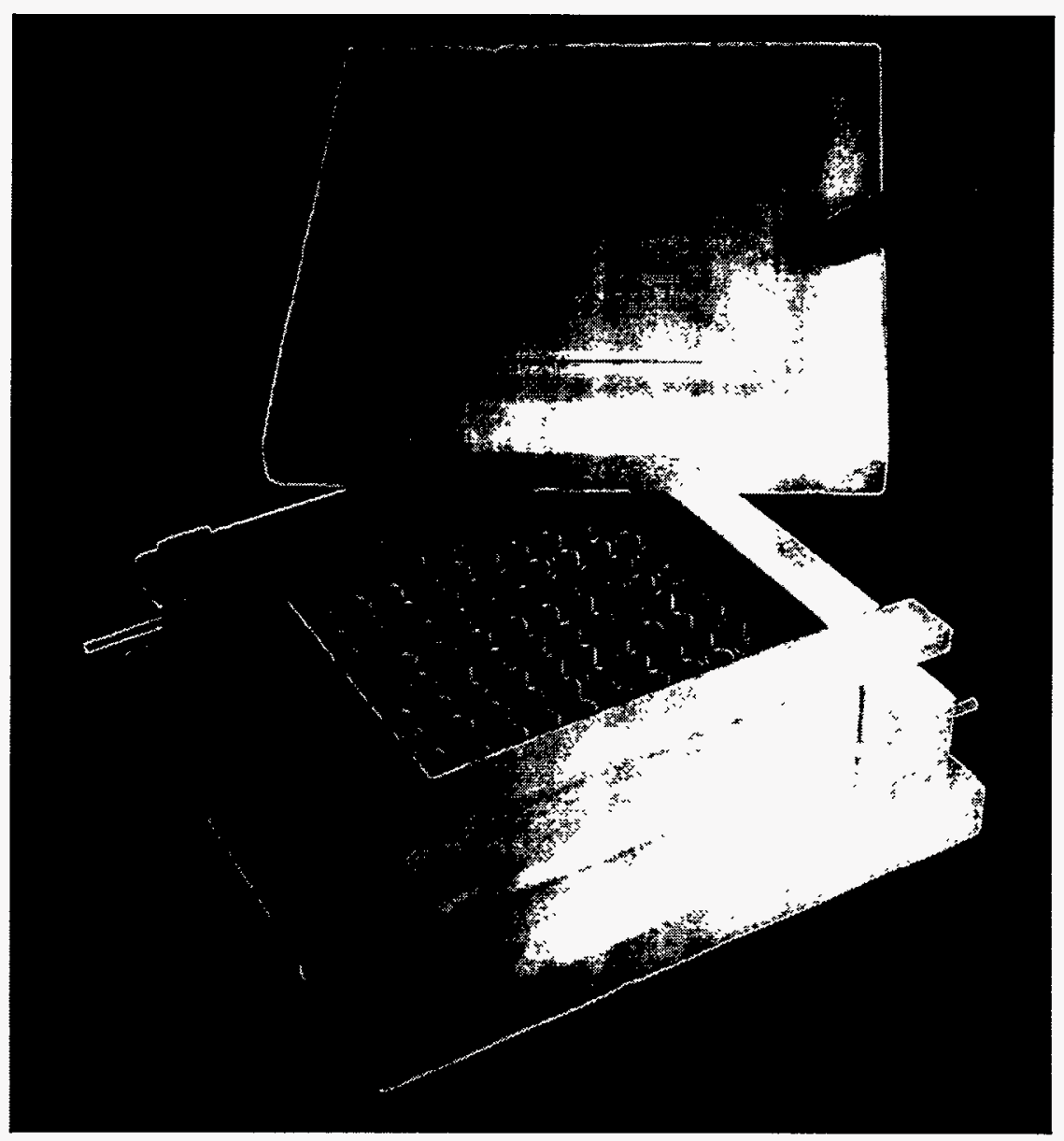

Fig. 1. Insulation package containing 90 clevis pins after nitridation using microwave heating.

Nitridation and Sintering Scale-up Study

The second study involved the scale-up of microwave nitridation and sintering of silicon preforms.

Table 2 summarizes important details and results concerning individual experiments. In experiment 1, eight bucket tappets were nitrided and sintered. A high density and a low standard deviation of the average density was obtained. Samples processed in experiment 7, using conventional heating, showed a similar sintered density and standard deviation. Experiments 2 through 6 were microwave scale-up runs with progressively larger numbers of samples. Varied 
average sintered densities were obtained due to sintering conditions chosen for the experiments. Slight warping of bucket tappet samples located in the corners of the crucible occurred in experiment 5, due the higher heat losses from the crucible corners. This problem could probably be solved through the use of a cylindrical crucible (no corners). In general, the standard deviation of the densities for these experiments increased as the sample number increased. Likewise, results in experiment 8 indicate that the same trend was true for scale-up runs using conventional heating. An examination of the microwave power data for experiments 2 through 6 shows that increasing power was required as the number of sample was increased. However, general conclusions relating power and sample number are not possible, since different sample types and insulation containers were used in various experiments. Figure 2 is a photo showing the arrangement of one layer of the total of three layers of bucket tappets and rectangular silicon preforms, as packaged inside a crucible for sample processing in microwave experiments 5 and 6 . Figure 3 is a photograph of the same samples after microwave processing. Figure 3 gives a good indication of the size of samples and the extent of the scale-up.

Table 2. Summary of conventional and microwave nitridation and sintering scale-up experiments

$\begin{array}{cccccccc}\text { Exp \# } & \begin{array}{c}\text { Furnace } \\ \text { Type }\end{array} & \begin{array}{c}\text { Furnace } \\ \text { Size }\end{array} & \text { Sample \# } & \begin{array}{c}\text { Total } \\ \text { Starting } \\ \text { Sample } \\ \text { Mass }(\mathrm{kg})\end{array} & \begin{array}{c}\text { Peak } \\ \text { Power } \\ (\mathrm{kW})\end{array} & \begin{array}{c}\text { Final } \\ \text { Sample } \\ \text { Density } \\ \left(\mathrm{g} / \mathrm{cm}^{3}\right)\end{array} & \begin{array}{c}\text { Standard } \\ \text { Deviation } \\ \text { Densities } \\ \left(\mathrm{g} / \mathrm{cm}^{3}\right)\end{array} \\ 1 & \text { microwave } & 500 \mathrm{~L} & 8^{\mathrm{a}} & 0.3 & 1.8 & 3.27 & 0.005 \\ 2 & \text { microwave } & 500 \mathrm{~L} & 21^{\mathrm{a}} & 0.7 & 3.7 & 3.23 & 0.002 \\ 3 & \text { microwave } & 500 \mathrm{~L} & 72^{\mathrm{b}} & 1.0 & 2.3 & 3.30 & 0.018 \\ 4 & \text { microwave } & 500 \mathrm{~L} & 108^{\mathrm{c}} & 1.1 & 5.2 & 3.25 & 0.008 \\ 5 & \text { microwave } & 4000 \mathrm{~L} & 90^{\mathrm{a}} & 2.9 & 2.6 & 3.18 & 0.020 \\ 6 & \text { microwave } & 4000 \mathrm{~L} & 230^{\mathrm{c}} & 2.1 & 2.9 & 3.19^{\mathrm{f}} & 0.019 \\ 7 & \text { resistance } & 70 \mathrm{~L} & 9^{\mathrm{a}} & 0.3 & - & 3.26 & 0.003 \\ 8 & \text { resistance } & 70 \mathrm{~L} & 210^{\mathrm{d}} & 2.9 & - & 3.22^{\mathrm{f}} & 0.052\end{array}$

${ }^{a}$ Cremer Forschung Institut bucket tappets, proprietary composition

${ }^{b}$ ORNL gelcast - isopressed material, $\mathrm{Si}_{3} \mathrm{~N}_{4}-9$ wt $\% \mathrm{La}_{2} \mathrm{O}_{3}-3$ wt $\% \mathrm{Al}_{2} \mathrm{O}_{3}$

CORNL gelcast - isopressed material, $\mathrm{Si}_{3} \mathrm{~N}_{4}-9 \mathrm{wt} \% \mathrm{Y}_{2} \mathrm{O}_{3}-3 \mathrm{wt} \% \mathrm{Al}_{2} \mathrm{O}_{3}$

${ }^{\mathrm{d}}$ Coors die pressed samples, proprietary composition

eND = not determined

fAverage density value, based on measurement of density of every fourth sample
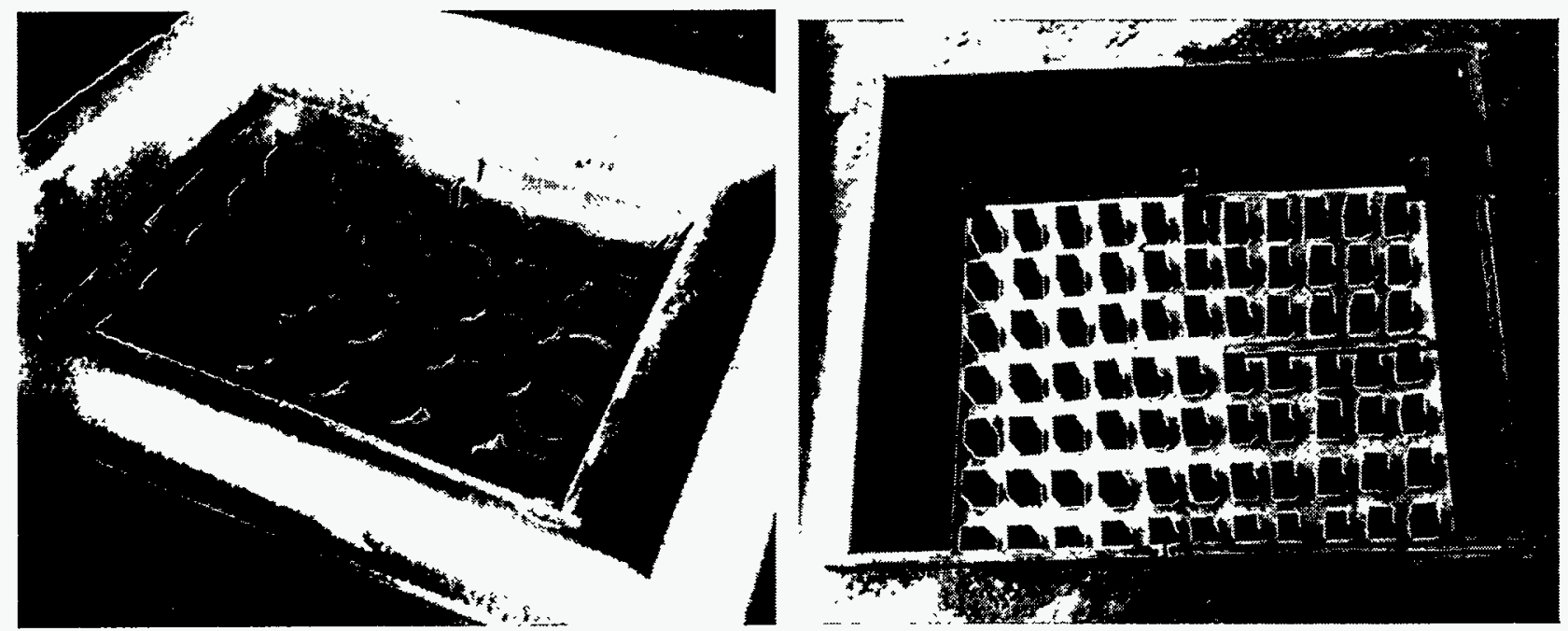

Fig. 2 Photos of silicon bucket tappet (left) and silicon gelcast rectangular bar preforms (right),as packaged for microwave scale-up experiments 5 and 6 , respectively. 

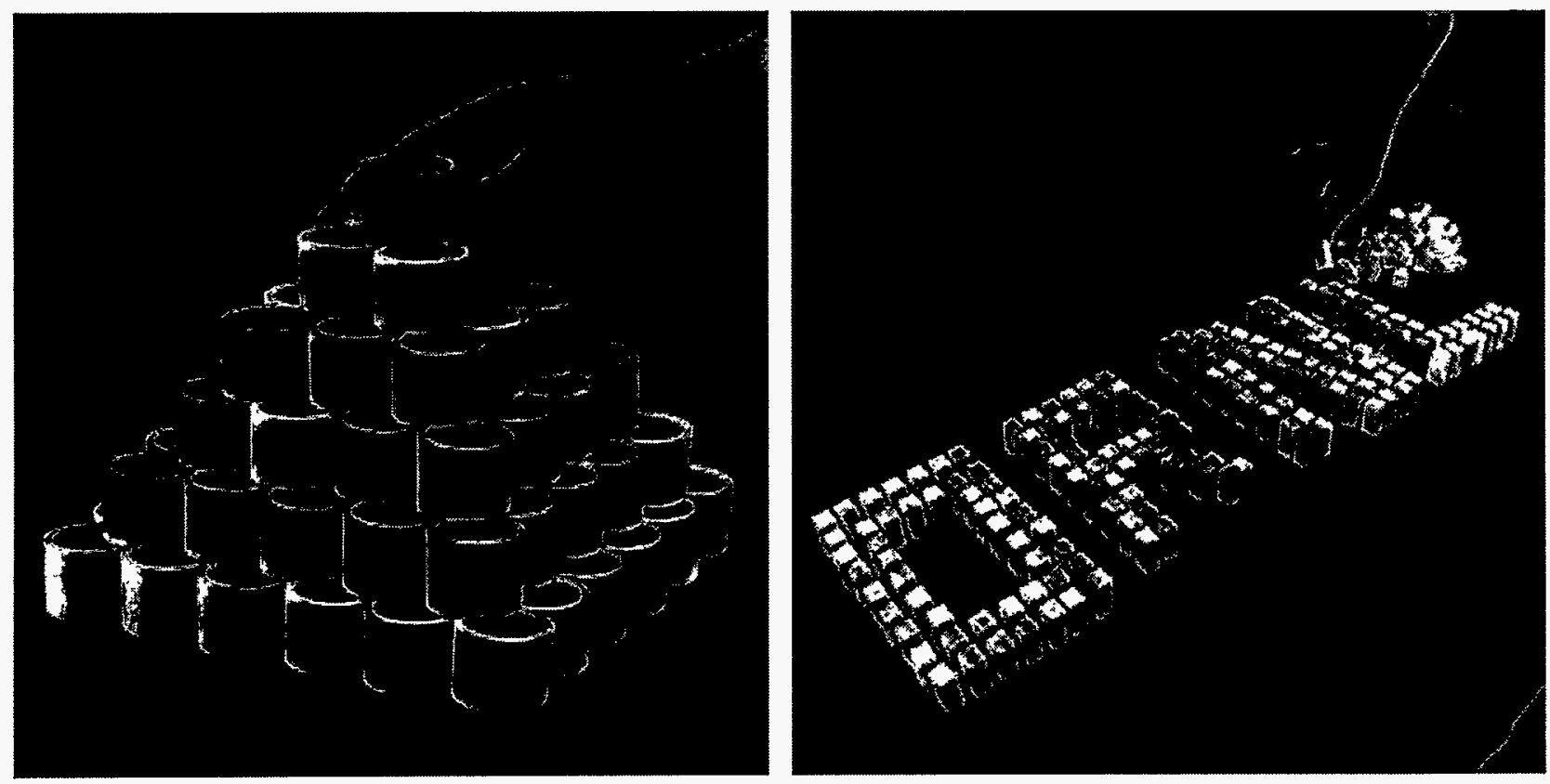

Fig. 3. Bucket tappet (left) and rectangular bar (right) SRBSN samples fabricated using microwave in experiments 5 and 6, respectively.

\section{Conclusion}

Scale-up was successfully demonstrated for microwave fabrication of reaction-bonded silicon nitride and sintered reaction-bonded silicon nitride. A variety of sizes, shapes, and compositions of silicon preforms were processed in the studies, including bucket tappets and clevis pins for diesel engines, with up to 230 samples processed at one time. Different sample packaging requirements were needed for microwave nitridation versus microwave sintering, since nitridation was done at a peak temperature $1300^{\circ} \mathrm{C}$, whereas nitridation and then sintering required peak temperatures of 1750 to $1800^{\circ} \mathrm{C}$.

Critical factors for success in both the microwave nitridation and sintering scale-up included proper sample spacing and selection of hybrid-heating crucible materials. These studies were meant to prove capability only. Additional refinements in the processes, such as the development of cylindrical hybrid-heating processing crucibles and the use of continuously moving microwave platforms, will be necessary for transfer of the microwave process to industry. It is believed that the lower microwave power requirements for microwave nitridation, $1 / 2$ the amount required for sintering, make it the more attractive of the two processes.

\section{REFERENCES}

1. R. N. Katz, Nitrogen Ceramics 1976-1981, pp. 3-20 in Progress in Nitrogen Ceramics, ed. F. L. Riley, Martinus Nijhoff Pub., The Hague, Netherlands (1983).

2. L. M. Sheppard, "Cost-Effective Manufacturing of Advanced Ceramics," pp. 692-707 in Am. Ceram. Soc. Bull., 70 [4] (1991).

3. T. Quadir, R. W. Rice, J. C. Chakraverty, J. A. Breindel, and C. C. Wu, "Development of Lower Cost $\mathrm{Si}_{3} \mathrm{~N}_{4}$," pp. 9-10 in Ceram. Eng. Sci. Proc., 12, 1952-1957 (1991). 